\title{
Effect of Sequential Electrospinning And Co- Electrospinning On Morphological And Fluid Mechanical Wall Properties of Polycaprolactone And Bovine Gelatin Scaffolds, For Potential Use In Small Diameter Vascular Grafts
}

Yuliet Montoya ( $\square$ yuliet.montoya@upb.edu.co)

Universidad Pontificia Bolivariana https://orcid.org/0000-0002-3763-3034

José Cardenas

Universidad Pontificia Bolivariana

John Bustamante

Universidad Pontificia Bolivariana

Raúl Valencia

Universidad Pontificia Bolivariana

Research article

Keywords: Small diameter vascular graft, sequential and co-electrospinning, morphology 52 of scaffolds, physicochemical properties, fluid-mechanical properties

Posted Date: August 5th, 2021

DOI: https://doi.org/10.21203/rs.3.rs-680589/v1

License: (c) (i) This work is licensed under a Creative Commons Attribution 4.0 International License.

Read Full License

Version of Record: A version of this preprint was published at Biomaterials Research on November 20th, 2021. See the published version at https://doi.org/10.1186/s40824-021-00240-8. 
1 Effect of sequential electrospinning and co-electrospinning on morphological and

2 fluid mechanical wall properties of polycaprolactone and bovine gelatin scaffolds,

3 for potential use in small diameter vascular grafts

4

5

6 Yuliet Montoya ${ }^{2,3}$, José Cardenas ${ }^{1,2}$, John Bustamante ${ }^{2,3}$, Raúl Valencia $^{1 *}$

7

8

9 'Grupo de Automática y Diseño A+D, Universidad Pontificia Bolivariana, Medellín,

10 Colombia

$11{ }^{2}$ Grupo de Dinámica Cardiovascular, Centro de Bioingeniería, Universidad Pontificia

12 Bolivariana, Medellín, Colombia

13 Comité de Trabajo de Bioingeniería Cardiovascular, Sociedad Colombiana de

14 Cardiología y Cirugía Cardiovascular, Bogotá, Colombia

15

$16{ }^{*}$ Corresponding Author

17 E-mail: raul.valencia@upb.edu.co

18 


\section{ABSTRACT}

Background: Nowadays, the engineering vascular grafts with a diameter less than $6 \mathrm{~mm}$ by means of electrospinning, is an attracted alternative technique to create different threedimensional microenvironments with appropriate physicochemical properties to promote the nutrient transport and to enable the bioactivity, dynamic growth and differentiation of cells. Although the performance of a well-designed porous wall is key for these functional requirements maintaining the mechanical function, yet predicting the flow rate and cellular transport are still not widely understood and many questions remain open about new configurations of wall can be used for modifying the conventional electrospun samples. The aim of the present study was to evaluate the effect of fabrication techniques on scaffolds composed of bovine gelatin and polycaprolactone (PCL) developed by sequential electrospinning and co-electrospinning, on the morphology and fluidmechanical properties of the porous wall.

Methodology: For this purpose, small diameter tubular structures were manufactured and experimental tests were performed to characterize the crystallinity, morphology, wettability, permeability, degradability, and mechanical properties. Some samples were cross-linked with Glutaraldehyde (GA) to improve the stability of the gelatin fiber. In addition, it was analyzed how the characteristics of the scaffold favored the levels of cell adhesion and proliferation in an in vitro model of T3T fibroblasts in incubation periods of 24,48 and $72 \mathrm{~h}$.

Results: It was found that in terms of the morphology of tubular scaffolds, the coelectrospun samples had a better alignment with higher values of fiber diameters and

41 apparent pore area than the sequential samples. The static permeability was more 
42 significant in the sequential scaffolds and the hydrophilic was higher in the co-electrospun

43 samples. Therefore, the gelatin mass losses were less in the co-electrospun samples, which promote cellular functions. In terms of mechanical properties, no significant 45 differences were observed for different types of samples.

Conclusion: This research concluded that the tubular scaffolds generated by sequential and co-electrospinning with modification in the microarchitecture could be used as a vascular graft, as they have better permeability and wettability, interconnected pores, and a circumferential tensile strength similar to native vessel compared to the commercial graft analyzed.

Keywords: Small diameter vascular graft, sequential and co-electrospinning, morphology of scaffolds, physicochemical properties, fluid-mechanical properties.

\section{INTRODUCTION}

Peripheral vascular disorders are associated with blockages and obstructions of small diameter vessels $(<6 \mathrm{~mm})$ leading to reduced blood flow and tissue detriment due to poor nutrient supply, therefore, angioplasty is commonly performed with the use of stents or surgical bypass grafts [1-3]. Each year, cardiovascular diseases generate about 17.9 million deaths [4]. Additionally, the number of invasive vascular procedures in the lower extremities has doubled in the last decade. For this type of pathologies, grafts of biological origin are usually used, such as autologous (from the same patient) and homologous (from a donor of the same species) [5], [6]. However, they have clinical disadvantages in their application due to a lack of donors, anatomical variability, or patients with previous interventions [7], [8]. Another option for vascular replacement is the use of grafts made of 
non-biodegradable polymers such as $\operatorname{Teflon}^{\circledR}$ or Dacron ${ }^{\circledR}$, which have been efficient in replacing large diameter vessels. However, when applied to the treatment of smaller vessels, they present complications related to thrombotic occlusion or intima hyperplasia due to their low biocompatibility [9].

In this sense, cardiovascular tissue engineering is key for the development of porous structures useful for replacing damaged tissues in the vascular system [10], [11], and for the evaluation of the biocompatibility of a variety of biomaterials [12], [10]. Biodegradable polymers of synthetic and natural origin [7], [11], are an alternative for the design of porous walls that provide a biological microenvironment that facilitates the development of new tissue while maintaining the mechanical function [12]. The study of natural polymers or proteins as electrospun scaffolds has gained great interest since they have the inherent ability to bind cells because they contain specific protein sequences (arginine, glycine and aspartic acid) [7], [8]. Therefore, synthetic and natural polymers can be combined to improve physical, chemical, and biological properties $[13,14]$. In this way, they increase biocompatibility with the cellular microenvironment, favoring a tissue functional response [15], [16].

Electrospinning has been shown as an alternative method for the development of scaffolds with nano and micro-fibrous morphology, more similar to a native extracellular matrix [17]. With this technique, it is possible to design porous walls using different configurations that allow to vary the morphological characteristics such as the diameter of fibers, their orientation, and the size of the pores. The spatial organization of fibers in these structures is a significant parameter for the integrity of the scaffold, porosity, and cellular behavior [18]. Using conventional electrospinning, scaffolds with homogeneous 
characteristics in their thickness are obtained, however, the wall of a native vessel has variable characteristics, for which configurations as the sequential electrospinning and co-electrospinning are modifications of the conventional electrospinning technique, to develop scaffolds with multiple layers or variable morphologies to imitate a specific morphology of extracellular matrix [19].

Besides, the electrospinning parameters allow variation in porosity through the combination of modification of pore diameter and fiber deposition [18]. It has been found that endothelial cells tend to align in the microfiber scaffold and to allow the penetration through the pores, while in the nanofiber scaffolds, the cells have a random growth with a minimum ability to infiltrate [20]. Additionally, the orientation of fibers in one direction minimizes the space between them, reducing the pore size; while that the alignment can be manipulated using a rotating collector with variable-speed or controlling the electric field [21, 22]. It has been reported that aligned fibers help in the orientation and elongation of smooth muscle cells through the longitudinal axis [23].

Static permeability is another property that allows relating to the performance of a vascular graft. It has been reported that values of hydraulic conductivity lower than 600 $\mathrm{mL} / \mathrm{cm}^{2} / \mathrm{min}$ limit the microcirculation of nutrients or biomolecules through the wall in hydrophobic grafts [24]. For scaffolds that exhibit hydrophilic behavior, this value may be lower since they allow to contain volumes of vascular fluid throughout its threedimensional structure, which allows an adequate molecular transport (oxygen, electrolytes, glucose, etc). In this way, polymers of natural origin such as proteins provide added value due to their hydrophilicity that allows an initial absorption of water [25]. 
Another challenge in the design of electrospun vascular grafts is to ensure adequate 111 properties of mechanical strength and elasticity to mimic those of a blood vessel [26].

112 Differences in mechanical properties can cause damage to endothelial cells, hyperplasia, 113 or ruptures in the device after implantation [27].

114 According to this context, the purpose of this study is to evaluate the effect of 115 sequential electrospinning and co-electrospinning on crystallinity and morphological 116 characteristics, permeability, wettability, degradability, and mechanical properties.

117 Additionally, the morphological and fluid-mechanical properties were characterized in a 118 commercial graft of $6 \mathrm{~mm}$ internal diameter and compared with the scaffolds developed 119 in this research.

\section{MATERIALS AND METHODS}

\subsection{Materials}

PCL (Mw: 80,000) pellets and bovine gelatin type b $(225 \mathrm{~g}$ bloom) were purchased from Sigma-Aldrich. N, N-dimethylformamide (DMF), dichloromethane (DCM), and acetic 124 acid were purchased from Panreac. GA $25 \% \mathrm{v} / \mathrm{v}$ for the crosslinking was purchased from 125 Protokimica, CO. All the solvents were used without further purification. The NIH/3T3 126 fibroblast cell line was purchased from the American Type Culture Collection (ATCC), and 127 Dulbecco's Modified Eagle's Medium (DMEM) and phosphate-buffered saline (PBS) were 128 obtained from Lonza. Fetal bovine serum (FBS) was purchased from Microgen and 129 hematoxylin - eosin was purchased from Thermo Fisher Scientific. 


\subsection{Electrospinning}

In this study, scaffolds were made using two types of electrospinning, in search of a microarchitecture for application in the vascular area. For sequential scaffolds, solutions of PCL $15 \%(\mathrm{w} / \mathrm{v})$ in DMF:DCM 1:1 and gelatin $25 \%(\mathrm{w} / \mathrm{v})$ in acetic acid $20 \%(\mathrm{v} / \mathrm{v})$ were loaded into $5 \mathrm{~mL}$ syringes with a $21 \mathrm{G}$ cutoff tip. 6 syringes of each solution were mounted on an infusion pump (Cole Parmer 60061), using PCL flows of $1.2 \mathrm{~mL} / \mathrm{h}$ and $0.8 \mathrm{~mL} / \mathrm{h}$. These samples were labeled as B0 and C0 respectively. In both cases, the gelatin flow was $0.3 \mathrm{~mL} / \mathrm{g}$. Initially. First, a volume of $2.2 \mathrm{~mL}$ per syringe of PCL solution was dispensed, followed by $0.8 \mathrm{~mL}$ of gelatin solution per syringe. Co-electrospun scaffolds were made dispensing simultaneously with the PCL and gelatin solutions. These samples were labeled as $\mathrm{B} 1$ using a $\mathrm{PCL}$ flow of $1.2 \mathrm{~mL} / \mathrm{h}$ and $\mathrm{C} 1$ for a $0.8 \mathrm{~mL} / \mathrm{h}$ flow. In all the cases for the PCL, a voltage of $18 \mathrm{kV}$ was applied to the solution using a power source (Gamma High Voltage Research 50PN) and a distance of $18 \mathrm{~cm}$ was set between the collector and the needles. A voltage of $15 \mathrm{kV}$ and a distance of $15 \mathrm{~cm}$ was used for the gelatin. Samples were collected in a $6 \mathrm{~mm}$ diameter rod wrapped with aluminum foil and grounded, rotating at a speed of $20 \mathrm{rpm}$. For mechanical characterization, tubular samples were collected using a $6 \mathrm{~mm}$ diameter cylinder wrapped with aluminum according to [28]. The relative humidity in all cases was in a range between $45 \%$ and $55 \%$ and the temperature was close to $30^{\circ} \mathrm{C}$. All the operating parameters were tested in a previous standardization work based on the literature [23, 29-35]. Table 1 summarizes all the operation parameters. 


\subsection{Crosslinking treatment}

The scaffolds were cross-linked with GA based on [36-39]. For this, a Petri plate was disposed in the bottom of a desiccator with $0.8 \mathrm{ml}$ of GA at $25 \% \mathrm{v} / \mathrm{v}$ in aqueous solution (these conditions were tested in a design of experiments not reported in this work). At the top of the desiccator, the samples were placed on a ceramic mesh. The desiccator was closed with a vacuum for 48 hours to allow cross-linking. This procedure is used to improve the stability of the gelatin fiber, in interaction with aqueous solvents, due to the union between the free amino groups of lysine or hydroxylysine residual amino acid present in the protein with the aldehydes of GA [39].

\subsection{FTIR}

To evaluate the effect of crosslinking, sequential and co-electrospun scaffolds were analyzed to determine changes in functional groups of the natural and synthetic polymer without and with treatment. For this, an infrared Fourier transform spectrophotometer with ATR module was used (FTIR, Thermo Scientific iS50) at a resolution of $4 \mathrm{~cm}^{-1}$ and 32 scans. Then, using the Origin Lab® software, the Fourier deconvolution of the infrared spectra covering the amide I region was performed $\left(1600-1700 \mathrm{~cm}^{-1}\right)$.

\subsection{Morphological characterization}

Samples were analyzed in a scanning electron microscope (SEM, JEOL JCM-6000 Plus) operating at $15 \mathrm{kV}$ to determine the morphological changes in the scaffolds. For each type of electrospun, three micrographs were processed and analyzed using the Fiji software with the plugin DiameterJ [40-42]. From the analysis of the micrographs, the following parameters were determined: fiber diameter, orientation, and apparent pore 
173 area. the segmentation algorithm applied to each micrography was based on the

174 methodology described in [41].

\section{3.6. Wettability}

The wettability of the membranes was measured by contact angle (Contact Angle 177 System OCA Dataphysics ${ }^{\circledR}$ ) based on ASTM D7334-08 [43], to determine the 178 hydrophilicity of scaffolds. For this test, a syringe dispenser was loaded with simulated 179 body fluid (SBF) fabricated according to [44]. Subsequently, a drop of $10 \mu \mathrm{L}$ of the solution was deposited on the sample, and photograms were captured for 30 seconds. For each

181 scaffold, a sample with dimensions $2 \mathrm{~cm} \times 5 \mathrm{~cm}$ was cut out and 4 drops were dispensed 182 over this. For this analysis, three replicates were used for each type of sample.

\subsection{Static permeability}

For the measurement of static permeability, the method stipulated in ISO7198 was adapted [45] with which the resistance to the passage of the flow through the microarchitecture of the scaffold wall was determined. The test bench consisted of a column of hydrostatic pressure, with a height of liquid equivalent to physiological, hypotensive and hypertensive pressures $(0$ to $150 \mathrm{mmHg}$ ). The test consisted of the measure of distilled water mass passing through the scaffolds by 1 minute, the scaffolds were arranged in a sample holder with a $1.1 \mathrm{~cm}$ of hole diameter. The evaluated

191 pressures were $50,80,120$, and $150 \mathrm{mmHg}$. To ensure the reproducibility of the results, 192 two replicates were analyzed for each type of membrane. With the results obtained, the 193 permeability was calculated using (1):

$$
K=\frac{m_{\text {fluid }}}{\rho_{\text {fluid }} \times A_{\text {hole }} \times t}
$$


where: $m_{\text {fluid }}$ distilled water mass [g], $A_{\text {hole }}$ hole area [ $\left.\mathrm{cm}^{2}\right], t$ time [s], $K$ permeability $\left[\mathrm{mL} / \mathrm{min} / \mathrm{cm}^{2}\right]$ and $\rho_{\text {fluid }}$ fluid density $[\mathrm{g} / \mathrm{mL}]$.

\subsection{Degradation}

The degradation rate of the membranes was evaluated in media with neutral $\mathrm{pH}$ to determine the loss of biomaterial in interaction with fluids. For the test, tubular segments with and without cross-linking treatment were used, with dimensions of $1.5 \mathrm{~cm}$ long by 6 $\mathrm{mm}$ in diameter. Then, the samples were immersed in phosphate-buffered saline solution (PBS) $1 \mathrm{X}$ during a time of 24,48 , and $72 \mathrm{~h}$ to measure the weight loss due to degradation [46]. To obtain reproducibility and repeatability, three replicates were analyzed for each 204 type of scaffold.

\subsection{Mechanical characterization}

The purpose of the test was to evaluate the circumferential tensile strength and creep elongation of bilayer membranes based on an adaptation of the standard ASTM D638 [47]. For the test 2 copper fasteners were used. Three tubular samples of each type of electrospun scaffold were cut with $2 \mathrm{~cm}$ length to be tested in a universal testing machine (Instron ${ }^{\circledR} 5582$ ) with a load cell of $1 \mathrm{kN}$ with a speed of $10 \mathrm{~mm} / \mathrm{min}$. To ensure

211 the reproducibility of the results, three replicates were analyzed for each type of 212 membrane.

\section{3.10. Cell adhesion and proliferation an in vitro model of 3T3 fibroblasts}

Cultures of 3T3 fibroblasts were maintained in DMEM media supplemented with $10 \%$ FBS, penicillin $(100 \mathrm{U} / \mathrm{ml})$, and streptomycin $(100 \mu \mathrm{g} / \mathrm{ml})$. The culture medium was

216 changed every three days, and the cell culture was maintained at $37^{\circ} \mathrm{C}, 5 \% \mathrm{CO}_{2}, 95 \%$ 
$217 \mathrm{O}_{2}$, and $95 \%$ relative humidity. Before the interaction of the membranes with the in vitro 218 model of 3T3 fibroblasts, these were sterilized and preconditioned with DMEM without 219 supplementation for $24 \mathrm{~h}$ at $37^{\circ} \mathrm{C}$. For the cell adhesion and proliferation assay, $22030 \times 10^{3}$ cells/well of 3 T3 fibroblast, with viability greater than $90 \%$, were seeded on the 221 cross-linked scaffolds for 24,48 , and $72 \mathrm{~h}$. After each incubation period, the scaffolds 222 were removed and fixed with $10 \%$ formaldehyde for $30 \mathrm{~min}$. Over time, it was added with 223 hematoxylin/eosin to stain plasma membranes and cell nuclei. Finally, frames were 224 obtained at $10 \mathrm{X}$ magnification using the Optika Vision Pro software, and cell proliferation 225 was determined from image processing with $I$ mage $J^{\circledR}$ software.

\subsection{Statistical analysis} variance, to determine the influence of each of the factors and their relationship with the fluid-mechanical properties. This was done using Statgraphics software. Data are presented as mean \pm standard deviation and a statistical significance of 0.05 was used.

\section{4. RESULTS}

\section{4.1. FTIR}

Figure 1 shows the normalized absorbance spectrum IR with the corrected baseline 234 for the gelatin layer of the sequential scaffolds with and without crosslinking and for a co235 electrospun scaffold. The FTIR analysis show the presence of the amide bands I, II, and III which are common structures in bovine gelatin and stretches of groups of $\mathrm{CH}_{2}, \mathrm{C}=\mathrm{O}$, 237 and C-O-C from PCL groups, as evidenced in Table 2. Due to the presence of all of these 238 stretches in the co-electrospun scaffold, the generation of a biocomposite material is 
239 determined. On the other hand, in the amide I, structures related to the stretching of the

$240-\mathrm{C}=\mathrm{N}-$ bond stretch are generated in the gelatin crosslinking with GA [48].

241 4.2. Morphological characterization

242

243

244

245

246

247

248

249

250

251

252

253

254

255

256 257 of $95 \%$ (Fig 2F).

258

259

260

261

The results of average fiber diameter and the distribution in the micrographs are shown in Figure 2. The histograms of the samples B0 and B1 fabricated with a flow of 1.2 $\mathrm{mL} / \mathrm{h}$ (Fig 2C and Fig 2D) had higher diameters (1.09 and $1.12 \mu \mathrm{m})$, although with a wider variability compared to $\mathrm{C} 0$ and $\mathrm{C} 1$ at a flow of $0.8 \mathrm{~mL} / \mathrm{h}(0.44$ and $0.74 \mu \mathrm{m})$ (Fig $2 \mathrm{~A}$ and Fig 2B). These results agree with $[12,15,17]$, where the fiber diameter is directly proportional to the solution flow. Additionally, a network of fibers with a smaller diameter around $0.15 \pm 0.041 \mathrm{~nm}$ corresponding to the gelatin is presented in the co-electrospun scaffolds. The average diameter of PCL fibers in co-electrospun scaffolds is greater than that of sequential scaffolds, possibly since the opposition of fields reduces the intensity of the voltage, therefore a lower level of tightening of fibers is obtained.

Due to the variation coefficient for the fiber diameter was greater than $20 \%$ for $\mathrm{B} 0$ and $\mathrm{C} 0$ in the PCL layer, and B1, Mood's median test were performed for the PCL flow and the electrospinning technique [50]. Since a P-value for the Chi-square test of 0.020 was lesser than 0.05 , it can be affirmed that the fiber diameters obtained after varying the technique and PCL flow have a statistically significant difference with a level of confidence

The cells and fibers of the extracellular matrix in most natural tissues exhibit welldefined patterns and specific spatial orientations [51]. Additionally, it has been reported that cell adhesion and proliferation is significantly improved in scaffolds with aligned morphologies since they allow to guide cell growth along the fibers. In order to analyze 
262 this behavior, the normalized frequency graphs for the fiber orientation angle were

263 obtained in Figure 3. It was found that the sequentially fabricated scaffolds generate fibers

264 with random directions due to multiple frequency peaks at different angle values were

265 observed. Unlike the co-electrospun scaffolds, there is a greater tendency to organize the

266 fibers in the vertical direction since a predominant peak at $-90^{\circ}$ and $90^{\circ}$ is observed in

267 both flow conditions. Because of the methodology used to determine fiber diameters is

268 difficult to determine the diameter of the small gelatin fibers present in the co-electrospun

269 scaffolds, an apparent pore area analysis was performed, which gives valuable

270 information about the processes of cellular infiltration to generate pseudo-endothelization

271 of the graft. Figure 4 shows the micrographs for each type of scaffold and it can be seen

272 that the fibrous structure of the gelatin layer of the sequential samples B0 and C0 is 273 preserved.

274 Table 3 shows the average apparent pore area measurement of electrospun 275 samples without and with treatment. It is found that the apparent pore area is reduced 276 due to the cross-linking treatment of about $60 \%$ and $49 \%$ in $\mathrm{B} 1$ and $\mathrm{C} 1$ samples 277 respectively. Despite this, the B1 scaffolds have an apparent pore area $46 \%$ greater than

$278 \mathrm{C} 1$ after treatment. On the gelatin layer in the sequential scaffolds, it was not possible to 279 determine the apparent pore area after treatment with the image processing software due 280 to swelling and bonds in the fibrous network.

281 The results show that varying from a flow of 0.8 to $1.2 \mathrm{~mL} / \mathrm{h}$, the diameter of the 282 fibers increases a greater percentage in the sequential configuration (145.6\%) compared 283 to the co-electrospinning $(49.8 \%)$. Working conditions leads to the flow has a greater 
284 effect on the diameter of the fibers when they are fabricated using the sequential 285 configuration.

286

287

288

289

290

291

292

293

294

295

296

297

298

299

300

301

302

303

304

305

\subsection{Wettability}

Figure $5 \mathrm{~A}$ and Figure $5 \mathrm{~B}$ show the contact angle as a function of time for untreated and crosslinked scaffolds respectively. For the gelatin layer in the scaffolds obtained by sequential electrospinning without treatment presented a contact angle lower than $10^{\circ}$ and was only detectable by the measuring software for $12 \mathrm{~s}$ before the drop was completely absorbed. Additionally, during the characterization of the gelatin layer wettability in the sequential samples, it was found that this protein dissolved upon contact with the drop of simulated body fluid which evidenced a low resistance in aqueous environments when they did not have the treatment. In contrast, when applying the crosslinking process, the contact angle was initially around $80^{\circ}$ and slowly decreased to stabilize with a value of about $20^{\circ}$ after $5 \mathrm{~s}$, evidencing a greater resistance to aqueous environments of the protein possibly due to the crystallinity level increased.

Additionally, with the analysis of variance according to the contact angle, it was found that the electrospinning technique affected with statistical significance because its $P$ value was 0.025 lesser than the test statistic 0.05 .

For the commercial graft (Fig 5A and Fig5B), a contact angle value of about $120^{\circ}$ was obtained and remained constant during the test. This is because the material of this graft is composed of a hydrophobic polymer (polytetrafluoroethylene) and possibly in its wall, the level of cell adhesion would be lesser because it is not less than $75^{\circ}$ as the literature suggests [54]. 
According to the results obtained, crosslinking increased the value of the contact angle in the gelatin layer in the sequential scaffolds by about $283 \%$ as seen in Fig $5 \mathrm{C}$ and Fig 5D, while in the co-electrospun scaffolds the contact angle value after the treatment decreased by about $61 \%$ compared to the un-crosslinked samples. On the other hand, when using a PCL flow of $1.2 \mathrm{~mL} / \mathrm{h}$ the crosslinking increased the contact angle value by $33 \%$ while using a flow of $0.8 \mathrm{~mL} / \mathrm{h}$ the change due to the crosslinking was $3 \%$.

\subsection{Static permeability}

Figure $6 \mathrm{~A}$ and Figure $6 \mathrm{~B}$ show the static permeability test as a function of hydrostatic pressure in a range of physiological and pathophysiological values for untreated and treated scaffolds respectively. These show that untreated scaffolds have a permeability in a range between $40-140 \mathrm{~mL} / \mathrm{min} / \mathrm{cm}^{2}$; while after the crosslinking treatment,

317 permeability falls in a range between $0-20 \mathrm{~mL} / \mathrm{min} / \mathrm{cm}^{2}$ for sequential scaffolds $\mathrm{B} 0, \mathrm{C}$, and co-electrospun $\mathrm{C} 1$, while the B1 scaffold has a tendency to increase and reaches a permeability of up to $70 \mathrm{~mL} / \mathrm{min} / \mathrm{cm}^{2}$ at a pressure of $150 \mathrm{mmHg}$. On the other hand, the commercial graft permeability was zero, except at $150 \mathrm{mmHg}$ where it had a permeability close to $50 \mathrm{~mL} / \mathrm{min} / \mathrm{cm}^{2}$. With an analysis of variance (ANOVA) for the static permeability,

322 it was found that all the main effects had a statistical significance because their P-value was lesser of $1 \times 10^{-4}$ for the technique, $\mathrm{PCL}$ flow, water pressure, and treatment and was 324 lower than the test statistic 0.05.

Furthermore, the effect of crosslinking according to the electrospinning technique is shown in Fig $6 \mathrm{C}$, where an average decrease in permeability around $72 \%$ is shown for co-electrospun scaffolds and $96 \%$ for sequential ones. The crosslinking had a greater effect on the sequential scaffolds because the gelatin layer formed a gel that when in 
329 contact with the water that sealed the structure and prevented the flow of water. On the

330 other hand, for the co-electrospun scaffolds, the gelatin fibers were not agglomerated in

331 a single layer but distributed throughout the three-dimensional structure of the wall,

332 avoiding the generation of an occlusion. The reduction in permeability was possibly

333 caused by the decrease in the average apparent pore area in the scaffolds. This same

334 behavior is observed in Fig $6 \mathrm{D}$ according to the PCL flow, where at a flow rate of $0.8 \mathrm{~m} / \mathrm{h}$

335 the permeability decreased an average of $94 \%$, while at a flow rate of $1.2 \mathrm{~mL} / \mathrm{h}$ the 336 decrease was $74 \%$.

337 The micrographs of the commercial graft show a discontinuous framework, which is 338 interrupted throughout the wall structure avoiding interconnectivity between pores. 339 Possibly due to this, in the static permeability tests values of $0 \mathrm{~mL} / \mathrm{min} / \mathrm{cm}^{2}$ were obtained 340 at pressures of 50,80 , and $120 \mathrm{mmHg}$, since it does not allow the flow of the fluid through 341 the wall. This type of graft probably does not favor cell infiltration or nutrients exchange 342 through its wall, because according to the literature [24], vascular grafts with hydrophobic 343 behavior must have permeability values greater than $600 \mathrm{~mL} / \mathrm{min} / \mathrm{cm}^{2}$ to ensure 344 microcirculation of nutrients or biomolecules through their wall.

\section{4.5. Degradation}

The loss of mass for scaffolds without GA treatment is shown in Fig 7A. It is

347 observed that the scaffolds lose about $6.8 \% \pm 2.9 \%$ of mass on average at $24 \mathrm{~h}$, but B1 348 losses the least mass with a value close to $3 \%$. This could be because the gelatin meshed 349 with the PCL fibers increases the tortuosity of the wall, which delay the dissolution of the 350 gelatin compared to the sequential scaffolds, where the gelatin layer is completely 351 exposed to the fluid. 
After 48 and 72 hours of the test, the average mass loss increased to $13.3 \% \pm 3.8 \%$ and $23 \% \pm 4.55 \%$ respectively. In this range of time, the $\mathrm{C} 1$ sample is the one that presents a greater loss of mass close to $19 \%$ and $28 \%$ respectively. A 355 possible cause for this behavior is that this scaffold had an initial gelatin/PCL ratio of 3.8:6.2 higher than the ratio of 2.9:7.1 for $\mathrm{B} 0, \mathrm{C} 0$, and $\mathrm{B} 1$ samples.

On the other hand, Fig 7B shows the average loss of mass for the crosslinked scaffolds close to $3.2 \%$ after 72 hours of testing. Again, it is observed that $\mathrm{C} 1$ samples had the greatest weight loss during the test, which may be due to the greater ratio of gelatin/PCL in this scaffold. In contrast, B1 had a lesser weight loss at all evaluated times, where possibly the tortuosity of the scaffolds protects the gelatin inside the wall. Additionally, an analysis of variance (ANOVA) for the mass loss was performed. It was found that the main effects PCL flow, crosslinking treatment, and immersion time had a statistical significance because their P-value was about $1 \times 10^{-4}$ and lesser than the test 365 statistic 0.05 . It should be noted that the value of the F-ratio in the effects of treatment and time were greater than the others, so these have a greater statistical weight.

Figure 7C shows the effect of crosslinking by the PCL flow, where there is evidence of a reduction in the average mass loss close to $14.4 \%$ for a flow of $0.8 \mathrm{~mL} / \mathrm{h}$ and 10.0 $\%$ for a flow of $1.2 \mathrm{~mL} / \mathrm{h}$. On the other hand, the interaction graph for crosslinking by the electrospinning technique is shown in Fig 7D.

In the analysis of variance (ANOVA), this interaction did not present statistically 372 significant importance, so it is observed that the sequential and co-electrospun curves 373 overlap, and the average loss of mass is reduced by about $12.2 \%$ due to crosslinking. 


\subsection{Mechanical characterization}

Figure $8 \mathrm{C}$ and Figure 8D show the stress vs. strain curves for each type of scaffold in the circumferential direction, both untreated and crosslinked respectively. It is observed in both figures that the $\mathrm{CO}$ samples are the scaffolds with greater tensile strength, although, after the cross-linking process, its tensile strength decreased by $15 \%$ while its yield elongation presented a change of $2.4 \%$, a value without statistical significance. On the other hand, the $\mathrm{CO}$ samples are the ones with the highest tensile strength because they have the smallest average fiber diameter.

To analyze the mechanical resistance data statistically, a variance test is performed with the data in Table 4, where a summary of the mechanical properties of yield elongation and tensile strength of tubular scaffolds are shown. With the Anova for the tensile strength, it was found that the technique and the flow are the effects with statistical significance because they have a P-value was $1 \times 10^{-5}$ and 0.016 respectively which are lesser than the test statistic of 0.05 . And an ANOVA test for the elongation was also applied and it was found that the electrospinning technique was the factor that had statistical significance with a P-value of 0.028 lesser than the test statistic of 0.05 .

Figure $8 \mathrm{E}$ shows the combined effects for tensile strength of factors between Treatment-Technique. It is found that tensile strength only decreased by $13 \%$ and $8 \%$ for sequential and co-electrospun scaffolds respectively, due to crosslinking.

Figure 8F shows the combined effects of yield elongation with the PCL flowtreatment. It was found that after the cross-linking procedure, ultimate elongation only increased $1 \%$ for sequential scaffolds and decreased $17 \%$ for co-electrospun scaffolds. 
As in the previous case of tensile strength, the effect of crosslinking is not statistically significant due to the lower proportion of gelatin in the scaffold compared to PCL. Finally, a tensile strength value was obtained close to $25 \mathrm{MPa}$ for the commercial graft (Fig 8B) ) and it has been reported that native vessels with diameters close to $6 \mathrm{~mm}$ have circumferential tensile strengths between 3 and $13 \mathrm{MPa}$ [26].

\subsection{Cell adhesion and proliferation}

Proliferation characteristics were determined at incubation periods of 24,48 , and $72 \mathrm{~h}$ of interaction between the cross-linked membranes and 3T3 fibroblasts. Fig. 9A shows the hematoxylin-eosin staining images, where it can be seen that 3T3 fibroblasts adhered to $\mathrm{B} 1$ and $\mathrm{C} 1$. This was due to the physicochemical and morphological conditions of the membranes where the incorporation of a protein with the presence of the amino acid sequence arginine-glycine-aspartic acid promotes cell adhesion since this sequence is recognized by integrins, that promote the union of cells with the extracellular matrix [62]. On the other hand, it was found that membrane $\mathrm{C} 1$ at incubation periods of 24,48 , and $72 \mathrm{~h}$ exhibits a cell growth rate of $30 \%, 17 \%$, and 52\% higher than B1 (Fig. 9B), respectively.

\section{DISCUSSION}

Efforts to obtain an adequate bioactivity, tissue engineering has promoted the use of polymeric structures of natural origin, which exhibit amorphous and crystalline structures. Derived from this, the use of bovine gelatin for the development of tubular structures, plays a major role in biocompatibility and pseudo-endothelialization processes. From the results, it is determined that deconvolution of the amide I band is more sensitive to changes in the content of secondary structures (beta turns and sheets) 
caused by crosslinking treatment. After the deconvolution, the area under the curve was obtained for the adjusted Gaussians around 1629, 1659, and $1693 \mathrm{~cm}^{-1}$, which represent the crystalline structures according to [29]. Furthermore, the percentage of these structures in the gelatin layer in sequentially electrospun scaffolds was found to around $49.8 \%$, while the sequential and co-electrospinning membranes exhibited an increase in the percentage of these crystalline structures after the crosslinking process with values of $55.9 \%$ and $66.2 \%$ respectively. Thus, it was found that, for the sequential scaffold with a crosslinked gelatin layer, the crystalline structures increased around $6 \%$ compared to the untreated scaffolds; meanwhile for the crosslinked co-electrospinning scaffolds, the increase was around $16 \%$.

Due to the co-electrospun scaffolds had a lesser amount of gelatin on the surface, compared to the layer of this protein in the sequential scaffolds, the co-electrospun scaffolds reach a higher level of crystallinity at the level on the surface, when reacting with the same amount of GA. In addition, the gelatin in the co-electrospun scaffolds possibly may take a longer time to degrade compared to the sequential scaffolds.

On the other hand, tubular structures exhibit a microstructural reorganization thanks to the interrelation of polycaprolactone with gelatin, trying to emulate the biomimetics of a native vessel. From the morphological point of view, although in [21] the fiber orientation was changed by varying the rotation speed of the collector mandrel, it can be seen that the fabrication technique could also affect this morphological characteristic. The effect of electric fields in the alignment of the fibers in electrospun scaffolds can be evidenced in [22], where they modified the ground connection of the collector to obtain aligned fibers. According to these results, due to the increase in the alignment of the fibers in co- 
442 electrospun scaffolds, the tensile strength could be favored [52], because the maximum 443 load in the direction of the fibers is increased.

Additionally, due to the presence of moisture during GA treatment, the morphology 445 of the fibers is affected, causing the fibers to bond at the points of attachment. Also, crosslinking involves the reaction of free amino groups present on amino acid residues of

447 polypeptide chains with the aldehyde group of GA, which generates a closeness of the 448 fibers and their swelling, causing a significant reduction in the apparent pore area. On the 449 other hand, in the co-electrospun scaffolds B1 and C1, the gelatin fibers are distributed 450 among the PCL fibers, which reduces the approach between gelatin fibers and a greater 451 apparent pore area.

452 Because in the sequential scaffolds there is an occlusion with almost zero pore area 453 values on the gelatin layer due to chemical treatment, cell adhesion and proliferation 454 could be lower and only at a superficial level, limiting wall penetration. While in the co455 electrospun scaffolds B1 and C1 that have a larger pore area, they could enhance cell 456 growth not only at the surface level but also inside the wall due to gelatin fibers are 457 distributed throughout the thickness [53]. On the other hand, the presence of gelatin in 458 these electrospun scaffolds possibly favors cell deposition as it contains amino acid 459 sequences that work like attachment points for cells [14]. Additionally, due to the 460 crosslinking treatment, the dissolution of the gelatin inside the scaffold would be avoided 461 on the initial days where the adhesion and cell proliferation are developed [39].

Wettability is an important factor for scaffold performance in tissue engineering 463 applications since hydrophilic surfaces with contact angles below $75^{\circ}$ have been found to 464 improve cell adhesion to the wall [54], [55]. For the PCL layer in the sequential scaffolds, 
465 contact angles greater than $110^{\circ}$ were obtained, which coincides with the literature due 466 to the nature of the apolar phase [56]. This characteristic was improved with the 467 incorporation of bovine gelatin in the polymer mixture.

468 On the other hand, the contact angle of the co-electrospun scaffolds without cross469 linking treatment tended to decrease from $110^{\circ}$ to a stable value between $30^{\circ}$ and $40^{\circ}$ 470 after 10 seconds. This behavior is probably due to both the gelatin and the PCL are 471 present throughout the scaffold wall and allow the absorption of the fluid to be slower 472 because the gelatin fibers are not fully exposed to the simulated body fluid. Additionally, 473 it is observed that B1 reaches a lower value than C1 possibly because its apparent pore 474 area is greater and would facilitate the absorption of the fluid. The decrease in contact 475 angle value for crosslinked co-electrospun scaffolds reaches a stabilization close to $20^{\circ}$ 476 after $15 \mathrm{~s}$. Similar results were reported in [23], [33] y [38], where contact angles between $47723-52^{\circ}$ were obtained for scaffolds fabricated with gelatin and a synthetic polymer like 478 PCL. Moreover, the time required to stabilize the contact angle value of crosslinked 479 scaffolds is longer compared to untreated scaffolds, which indicates a lower degradation 480 of the protein in aqueous media [57]. Following this further, it has been reported that to ensure adequate cell infiltration 482 and exchange of nutrients or biomolecules between cells in vascular graft, interconnected 483 porosities are required [35], [58], which allows controlled permeability. It has been found 484 that a hydrophilic wall allows containing a volume of vascular fluid between its structure, 485 which makes possible an adequate molecular transport [24]. In the co-electrospun scaffolds, the presence of gelatin and after the cross-linking 487 treatment, it is possible to retain a volume of water inside the wall which would allow 
488 continuous molecular transport by diffusion. Additionally, because gelatin has a rapid 489 degradation in aqueous environments, the apparent pore area of these scaffolds would 490 increase after a short period and possibly would facilitate cell proliferation [14]. In 491 sequential scaffolds with cross-linking treatment, the occlusion that occurs on the gelatin 492 layer could avoid the need to perform the pre-coagulation process and allow retaining 493 vascular fluid in the wall [24].

$494 \quad$ Following this further, a mass loss test was performed on tubular scaffolds, to 495 determine the effect of the cross-linking process on the time in which the gelatin is 496 available within the electrospun scaffolds after being in contact with an aqueous medium.

497 These results demonstrate that the cross-linking treatment probably prevents the gelatin 498 mass loss in the initial days after a scaffold is implanted as a vascular graft since several 499 physicochemical phenomena associated with biological stages of tissue development 500 occur at different time scales [39]. It has been reported, for example, that cell adhesion 501 develops for hours, while proliferation and differentiation occur on a scale between days 502 and weeks $[56,59]$. Therefore, the B1 membrane could have a better performance 503 because it loses a lower mass of gelatin, which would favor cell proliferation and 504 differentiation in the initial days and weeks.

505 Vascular grafts must ensure adequate properties of mechanical strength and 506 elasticity to mimic the structure of the native blood vessel [26]. The effect of crosslinking 507 did not generate statistically significant differences, possibly because the treatment 508 affects only the gelatin fibers which are found in a smaller proportion than PCL fibers [52]. 509 This synthetic polymer is responsible for giving mechanical integrity to the tubular 510 scaffolds [24]. 
In this way, it was observed that the scaffolds with the smallest average fiber 512 diameter and average apparent pore area corresponding to those made with the 513 sequential technique had the highest tensile strength $[36,58,60]$. These results indicate 514 that the predominant effect on the mechanical properties of these tubular scaffolds is the 515 morphological characteristics of the PCL because the proportion of gelatin is much lower 516 and because of its low mechanical strength, and the crosslinking treatment is not 517 significant for this property [14]. Besides, intimal hyperplasia may occur due to a 518 compliance mismatch between the graft and native vessel [26, 61], [27] and the 519 elongation effect should be considered as another failure parameter of these tubular 520 scaffolds.

521 The scaffolds obtained in the present work are within the range of the native vessels 522 compared to the commercial sample analyzed with a diameter of $6 \mathrm{~mm}$, conditions that 523 would possibly avoid generating complications such as distal mechanical trauma, 524 atheromatous or hardening of the blood vessel [1].

525 Finally, from the cellular behavior B1 has $46 \%$ of apparent pore area greater than $526 \mathrm{C} 1$, which prevents a homogeneous cellularization from being generated on the 527 electrospun scaffold, since the reticulated B1 membrane exhibits two different layers of 528 fibers that are not interrelated with each other, generating a larger pore that prevents cell529 cell communication [63]. While, $\mathrm{C} 1$ has a smaller pore size, allowing adhesion, 530 proliferation, and generation of fibroblast syncytium. In addition, the crosslinked C1 531 membranes present a hybrid fibrillar network, which exhibits micrometric-scale fibers that 532 generate large pores that allow cells to freely infiltrate the membrane, and nanometric 533 fibers that facilitate cell adhesion and proliferation [64]. 


\section{CONCLUSIONS}

Our results allowed us to determine the effect of wall morphological characteristics of scaffolds obtained by different electrospinning methods, composed of a synthetic

537 polymer and a protein, on the fluid-mechanical properties evaluated in an in vitro model, 538 for their potential use as vascular grafts with a diameter of $6 \mathrm{~mm}$. For this purpose, a 539 synthetic polymer such as PCL was used taking advantage of its mechanical properties, 540 and a protein as bovine gelatin that improves hydrophilicity and increases 541 biocompatibility. However, this protein is rapidly degraded in aqueous environments, for 542 which a crosslinking process with GA was carried out. It was found an increase in the 543 percentage of beta sheets and turns due to the crosslinking treatment and the rapid 544 dissolution of bovine gelatin when interacting with an aqueous medium would be avoided. 545 In the same way, co-electrospun samples presented a lower mass loss of gelatin, which 546 would possibly favor the attachment points with the cells due to the amino acid sequences 547 of the gelatin. Additionally, the average diameter, the alignment of fibers and the apparent 548 pore area in co-electrospun samples had higher values which improve the cell growth 549 along the scaffold.

550 It was found that the reticulated membranes favor the adhesion and proliferation of 551 T3T fibroblasts, which indicates that the type of co-electrospinning techniques generates 552 biocompatible hybrid fibrillar morphologies. Additionally, the co-electrospinning technique 553 with the lower flux of PCL changes the microarchitecture with a morphology that favors 554 anchoring sites for syncytium that with the time, homogeneously cellularize the surface 555 of the scaffold. 
Finally, the tubular scaffolds obtained by sequential or co-electrospinning had a 557 better performance as vascular grafts than the commercial sample analyzed for 558 applications with internal diameters of $6 \mathrm{~mm}$, since they have better permeability and 559 wettability, interconnected pores and a circumferential tensile strength that is more similar 560 to that of a native vessel.

561 7. DECLARATIONS

562 ETHICS APPROVAL AND CONSENT TO PARTICIPATE

This research has the approval of the Ethics Committee of the Universidad

564 Pontificia Bolivariana.

565 CONSENT FOR PUBLICATION

566 The manuscript has been submitted with the consent of all authors for 567 publication.

\section{AVAILABILITY OF DATA AND MATERIALS}

All relevant data are within the paper and its Supporting Information files. 
The authors declare that they have no relation, condition, or circumstance that

572 constitutes a potential conflict of interest.

FUNDING

This research was supported by the Universidad Pontificia Bolivariana for the academic support in the formation of a student resource committed in the present research work. Also, to the Department of Science, Technology and InnovationCOLCIENCIAS, Colombia (projects No. FP44842-500-2014 and No. 121084467592). The funders had no role in study design, data collection and analysis, decision to publish, or preparation of the manuscript.

\section{AUTHORS' CONTRIBUTIONS}

YM: conceptualization and design of this study, formal analysis, funding acquisition and resources, supervision, writing - original draft, writing - review \& editing.

JC: formal analysis, investigation, writing - original draft.

JB: conceptualization and design of this study, formal analysis, funding acquisition and resources, project administration, supervision, writing - original draft, writing review \& editing. 
The authors thank the Universidad Pontificia Bolivariana for scholarship support to

592 a member of the research and the Department of Science, Technology and Innovation-

593 COLCIENCIAS, Colombia, for financial support for student resources through the national 594 doctorate 647 of 2014. Also, thanks to the Centro de Investigación en Materiales 595 Avanzados - CIMAV (México) for the service for the FTIR characterization.

596

\section{REFERENCES}

598 [1] Carrabba M, Madeddu P. Current Strategies for the Manufacture of Small Size 599 Tissue Engineering Vascular Grafts. Front Bioeng Biotechnol 2018; 6: 41.

600

601

[2] Yazdanpanah A, Tahmasbi M, Amoabediny G, et al. Fabrication and characterization of electrospun poly- L -lactide/gelatin graded tubular scaffolds:

602 Toward a new design for performance enhancement in vascular tissue engineering. Prog Nat Sci Mater Int 2015; 25: 405-413.

604

[3] Stefani I, Cooper-White JJ. Development of an in-process UV-crosslinked, 605 606 electrospun PCL/aPLA-co-TMC composite polymer for tubular tissue engineering applications. Acta Biomater 2016; 36: 231-240.

607 [4] World Health Organization. Cardiovascular diseases (CVDs).

608 [5] Greisler HP. Vascular grafts: experiment and modeling. J Vasc Surg 2003; 38: 609 1144.

610 [6] Capulli AK, MacQueen LA, Sheehy SP, et al. Fibrous scaffolds for building hearts 611 and heart parts. Adv Drug Deliv Rev 2016; 96: 83-102.

612 [7] Fukunishi T, Shoji T, Shinoka T. Nanofiber composites in vascular tissue 
engineering. In: Nanofiber Composites for Biomedical Applications. Elsevier Ltd, 2017, pp. 455-481.

615 [8] Bergmeister $\mathrm{H}$, Strobl M, Grasl C, et al. Tissue engineering of vascular grafts. Eur 616 Surg 2013; 45: 187-193.

617 [9] Zeng W, Li Y, Wang Y, et al. Tissue engineering of blood vessels. Elsevier Inc., 618 619 620 621

622 623

624

625

626

627

628

629

630

631

632

633

634 635

2019. Epub ahead of print 2019. DOI: 10.1016/B978-0-12-801238-3.65848-8.

[10] Huang ZM, Zhang $Y Z$, Kotaki $M$, et al. A review on polymer nanofibers by electrospinning and their applications in nanocomposites. Compos Sci Technol 2003; 63: 2223-2253.

[11] Hiob MA, Crouch GW, Weiss AS. Elastomers in vascular tissue engineering. Curr Opin Biotechnol 2016; 40: 149-154.

[12] Sill TJ, von Recum HA. Electrospinning: Applications in drug delivery and tissue engineering. Biomaterials 2008; 29: 1989-2006.

[13] Norouzi SK, Shamloo A. Bilayered heparinized vascular graft fabricated by combining electrospinning and freeze drying methods. Mater Sci Eng C 2019; 94: 1067-1076.

[14] Heidari M, Bahrami SH, Ranjbar-Mohammadi M, et al. Smart electrospun nanofibers containing PCL/gelatin/graphene oxide for application in nerve tissue engineering. Mater Sci Eng C 2019; 103: 109768.

[15] Bhardwaj N, Kundu SC. Electrospinning: A fascinating fiber fabrication technique. Biotechnol Adv 2010; 28: 325-347.

[16] Bhaarathy V, Venugopal J, Gandhimathi C, et al. Biologically improved nanofibrous scaffolds for cardiac tissue engineering. Mater Sci Eng C 2014; 44: 268-277. 
[17] Ramakrishna S, Fujihara K, Teo W-E, et al. An Introduction to Electrospinning and Nanofibers. Singapore: WORLD SCIENTIFIC, 2005. Epub ahead of print June 2005. DOI: $10.1142 / 5894$.

[18] Lee S, Yoo J. Guidance of Cell Adhesion, Alignment, Infiltration and Differentiation on Electrospun Nanofibrous Scaffolds. In: Khang G (ed) Handbook of Intelligent Scaffold for Tissue Engineering and Regenerative Medicine. Pan Stanford Publishing, pp. 201-217.

[19] Szentivanyi A, Chakradeo T, Zernetsch H, et al. Electrospun cellular microenvironments: Understanding controlled release and scaffold structure. Advanced Drug Delivery Reviews 2011; 63: 209-220.

[20] Soliman S, Sant S, Nichol JW, et al. Controlling the porosity of fibrous scaffolds by modulating the fiber diameter and packing density. J Biomed Mater Res Part A 2011; 96A: 566-574.

[21] Courtney T, Sacks M, Stankus J, et al. Design and analysis of tissue engineering scaffolds that mimic soft tissue mechanical anisotropy. Biomaterials 2006; 27 : $3631-3638$.

[22] Tan Z, Gao X, Liu T, et al. Electrospun vein grafts with high cell infiltration for vascular tissue engineering. Mater Sci Eng C 2017; 81: 407-415.

[23] Shalumon KT, Deepthi S, Anupama MS, et al. Fabrication of poly (I-lactic acid)/gelatin composite tubular scaffolds for vascular tissue engineering. Int J Biol Macromol 2015; 72: 1048-1055.

[24] Nagiah N, Johnson R, Anderson R, et al. Highly Compliant Vascular Grafts with Gelatin-Sheathed Coaxially Structured Nanofibers. Langmuir 2015; 31: 12993- 
13002.

660

661

662

663

664

665

666

667

668

669

670

671

672

673

674

675

676

677

678

679

680

681

[25] Suresh S, Gryshkov O, Glasmacher B. Impact of setup orientation on blend electrospinning of poly-\$£\$-caprolactone-gelatin scaffolds for vascular tissue engineering. Int J Artif Organs 2018; 41: 801-810.

[26] Jirofti N, Mohebbi-Kalhori D, Samimi A, et al. Small-diameter vascular graft using co-electrospun composite PCL/PU nanofibers. Biomed Mater 2018; 13: 55014.

[27] He W, Yong T, Teo WE, et al. Fabrication and Endothelialization of CollagenBlended Biodegradable Polymer Nanofibers: Potential Vascular Graft for Blood Vessel Tissue Engineering. Tissue Eng 2005; 11: 1574-1588.

[28] Sohrabi A, Naderi M, Gorjipour F, et al. A new design for electrospinner collecting device facilitates the removal of small diameter tubular scaffolds and paves the way for tissue engineering of capillaries. Exp Cell Res 2016; 347: 60-64.

[29] Xue Y, Sant V, Phillippi J, et al. Biodegradable and biomimetic elastomeric scaffolds for tissue-engineered heart valves. Acta Biomater 2017; 48: 2-19.

[30] Correia TR, Ferreira P, Vaz R, et al. Development of UV cross-linked gelatin coated electrospun poly(caprolactone) fibrous scaffolds for tissue engineering. Int $\mathrm{J}$ Biol Macromol 2016; 93: 1539-1548.

[31] McClure MJ, Sell SA, Simpson DG, et al. A three-layered electrospun matrix to mimic native arterial architecture using polycaprolactone, elastin, and collagen: A preliminary study. Acta Biomater 2010; 6: 2422-2433.

[32] Okutan N, Terzi P, Altay F. Affecting parameters on electrospinning process and characterization of electrospun gelatin nanofibers. Food Hydrocoll 2014; 39: 19 26. 
682 [33] Jiang Y-C, Jiang L, Huang A, et al. Electrospun polycaprolactone/gelatin 683 composites with enhanced cell-matrix interactions as blood vessel endothelial layer scaffolds. Mater Sci Eng C 2017; 71: 901-908.

685

686

687

688

689

690

691

692

693

694

695

696

697

698

699

700

701

702

703

704

[34] He W, Ma Z, Wee ET, et al. Tubular nanofiber scaffolds for tissue engineered smalldiameter vascular grafts. J Biomed Mater Res - Part A 2009; 90: 205-216.

[35] Tan Z, Wang H, Gao X, et al. Composite vascular grafts with high cell infiltration by co-electrospinning. Mater Sci Eng C 2016; 67: 369-377.

[36] Ju YM, Choi JS, Atala A, et al. Bilayered scaffold for engineering cellularized blood vessels. Biomaterials 2010; 31: 4313-4321.

[37] Montero RB, Vial X, Nguyen DT, et al. bFGF-containing electrospun gelatin scaffolds with controlled nano-architectural features for directed angiogenesis. Acta Biomater 2012; 8: 1778-1791.

[38] Wu T, Huang C, Li D, et al. A multi-layered vascular scaffold with symmetrical structure by bi-directional gradient electrospinning. Colloids Surfaces $B$ Biointerfaces 2015; 133: 179-188.

[39] Zhang YZ, Venugopal J, Huang Z-M, et al. Crosslinking of the electrospun gelatin nanofibers. Polymer (Guildf) 2006; 47: 2911-2917.

[40] DiameterJ.

[41] Learn DiameterJ.

[42] Java. ImageJ: Image processing and analysis in Java.

[43] (ASTM). D7334 - 08, Standard Practice for Surface Wettability of Coatings , Substrates and Pigments by Advancing Contact Angle Measurement. Annu B ASTM Stand. Epub ahead of print 2008. DOI: 10.1520/D7334-08. 
705 [44] Kokubo T, Takadama H. How useful is SBF in predicting in vivo bone bioactivity? Biomaterials 2006; 27: 2907-2915.

707 708

[45] International Organization for Standarization. Cardiovascular implants, Tubular vascular prostheses ISO 7198. 1998; 50.

[46] Badhe R V., Bijukumar D, Chejara DR, et al. A composite chitosan-gelatin bilayered, biomimetic macroporous scaffold for blood vessel tissue engineering. Carbohydr Polym 2017; 157: 1215-1225.

[47] ASTM-D638-14. Standard Test Method for Tensile Properties of Plastics. ASTM Stand.

[48] Huang C, Chen R, Ke Q, et al. Electrospun collagen-chitosan-TPU nanofibrous scaffolds for tissue engineered tubular grafts. Colloids Surfaces B Biointerfaces 2011; 82: 307-315.

[49] Muyonga JH, Cole CGB, Duodu KG. Fourier transform infrared (FTIR) spectroscopic study of acid soluble collagen and gelatin from skins and bones of young and adult Nile perch (Lates niloticus). Food Chem 2004; 86: 325-332.

[50] Corder GW, Foreman DI. Nonparametric statistics : a step-by-step approach. John Wiley \& Sons, Inc., 2014.

[51] Laurencin CT, Nair LS. Nanotechnology and Regenerative Engineering. 2015. Epub ahead of print 2015. DOI: 10.1017/CBO9781107415324.004.

[52] Tsai S-W, Yu Y-L, Hsu F-Y. Fabrication of polycaprolactone tubular scaffolds with an orthogonal-bilayer structure for smooth muscle cells. Mater Sci Eng C 2019; 100: $308-314$.

[53] Jun I, Han HS, Edwards JR, et al. Electrospun fibrous scaffolds for tissue 
engineering: Viewpoints on architecture and fabrication. International Journal of Molecular Sciences 2018; 19: 745.

[54] Chen X, Wang J, An Q, et al. Electrospun poly(I-lactic acid-co-e-caprolactone) fibers loaded with heparin and vascular endothelial growth factor to improve blood compatibility and endothelial progenitor cell proliferation. Colloids Surfaces $B$ Biointerfaces 2015; 128: 106-114.

[55] Wang H, Feng Y, Yuan W, et al. Fabrication and characterization of electrospun biocompatible PU/PEGMA hybrid nanofibers by in-situ UV photopolymerization. Sci China Physics, Mech Astron 2012; 55: 1189-1193.

[56] Bordes C, Fréville V, Ruffin E, et al. Determination of poly $(\$ \varepsilon \$$-caprolactone) solubility parameters: Application to solvent substitution in a microencapsulation process. Int J Pharm 2010; 383: 236-243.

[57] Kharazi AZ, Atari M, Vatankhah E, et al. A nanofibrous bilayered scaffold for tissue engineering of small-diameter blood vessels. Polym Adv Technol 2018; 1-8.

[58] Bergmeister $\mathrm{H}$, Schreiber C, Grasl C, et al. Healing characteristics of electrospun polyurethane grafts with various porosities. Acta Biomater 2013; 9: 6032-6040.

[59] Madhavan K, Belchenko D, Motta A, et al. Evaluation of composition and crosslinking effects on collagen-based composite constructs. Acta Biomater 2010; 6: 1413-1422.

[60] Li X, Wang X, Yao D, et al. Effects of aligned and random fibers with different diameter on cell behaviors. Colloids Surfaces B Biointerfaces 2018; 171: 461-467.

[61] Mi HY, Jiang $Y$, Jing $X$, et al. Fabrication of triple-layered vascular grafts composed of silk fibers, polyacrylamide hydrogel, and polyurethane nanofibers with 
761

762

763

764

765

766

767

768

769

770

771

63

biomimetic mechanical properties. Mater Sci Eng C 2019; 98: 241-249.

[62] Aldana AA, Abraham GA. Current advances in electrospun gelatin-based scaffolds for tissue engineering applications. Int J Pharm 2017; 523: 441-453.

[63] Dubey S, Mishra R, Roy P, et al. 3-D macro/microporous-nanofibrous bacterial cellulose scaffolds seeded with BMP-2 preconditioned mesenchymal stem cells exhibit remarkable potential for bone tissue engineering. Int J Biol Macromol 2021; 167: 934-946.

[64] Ameer JM, Anil Kumar PR, Kasoju N. Strategies to tune electrospun scaffold porosity for effective cell response in tissue engineering. J Funct Biomater 2019; 10: 1-21.

(1)

2




\section{FIGURE LEGENDS}

773 Figure 1. Normalized FTIR spectra.

774 Figure 2. Histograms of the distribution of fiber diameter: A) sample with a flow of 0.8 $775 \mathrm{~mL} / \mathrm{h}$ in the sequential configuration; B) sample with a flow of $0.8 \mathrm{~mL} / \mathrm{h}$ in the co776 electrospinning configuration; C) sample with a flow of $1.2 \mathrm{~mL} / \mathrm{h}$ in the sequential 777 configuration; D) sample with a flow of $1.2 \mathrm{~mL} / \mathrm{h}$ in the co-electrospinning configuration; 778 E) gelatin layer in the sequential configuration; F) Interaction graph between technique 779 and flow.

780 Figure 3. Normalized global frequency graphs of the fiber orientation. The fiber of 781 sequential scaffolds shows multiple peaks of relative frequency, while in co-electrospun 782 scaffolds predominant peaks are observed around $90^{\circ}$, indicating a greater alignment.

783 Figure 4. Comparison of SEM micrographs of the electrospun scaffold, before and after 784 the crosslinking treatment.

785 Figure 5. Contact angle vs. time curves: A) Electrospun scaffolds without crosslinking; B) 786 Crosslinked electrospun scaffolds; C) Interaction graph according to the PCL flow;

787 D) Interaction graph according to the technique.

788 Figure 6. Static permeability: A) Electrospun scaffolds without crosslinking; B) 789 Crosslinked electrospun scaffold; C) Interaction graph according to the technique; D) 790 Interaction graph according to the PCL flow $(\mathrm{mL} / \mathrm{h})$.

791 Figure 7. Mass loss of electrospun scaffolds: A) samples without treatment; B) cross792 linked samples; C) Interaction graph according to the technique; D) Interaction graph 793 according to the PCL flow ( $\mathrm{mL} / \mathrm{h})$. 
794 Figure 8. Stress curves vs deformation for tubular scaffolds: A) test of traction; B) 795 commercial sample; C) sample without treatment; D) sample with crosslinking treatment; 796 E) Interaction graph for tensile strength according to the technique; F) Interaction graph 797 for yield elongation according to the technique

798 Figure 9. Cross-linked B1 and C1 membranes interacting with 3T3 fibroblasts:A) bright799 field images of fibroblasts; B) cell growth rate at incubation periods of 24,48 , and $72 \mathrm{~h}$.

800

801 TABLES

802 Table 1. Summaries of electrospinning operation parameter

\begin{tabular}{|c|c|c|c|c|c|c|c|c|}
\hline Scaffold name & \multicolumn{2}{|c|}{ B0 } & \multicolumn{2}{|r|}{$\mathrm{CO}$} & \multicolumn{2}{|c|}{ B1 } & \multicolumn{2}{|l|}{ C1 } \\
\hline Polymer & PCL & Gelatin & PCL & Gelatin & PCL & Gelatin & PCL & Gelatin \\
\hline Technique & \multicolumn{4}{|c|}{ sequential electrospinning } & \multicolumn{4}{|c|}{ co-electrospinning } \\
\hline Flow (mL/h) & 1.2 & 0.3 & 0.8 & 0.3 & 1.2 & 0.3 & 0.8 & 0.3 \\
\hline Voltage (kV) & 18 & 15 & 18 & 15 & 18 & 15 & 18 & 15 \\
\hline Needle-rod gap $(\mathrm{cm})$ & 18 & 15 & 18 & 15 & 18 & 15 & 18 & 15 \\
\hline Rod diameter $(\mathrm{cm})$ & \multicolumn{8}{|c|}{0.6} \\
\hline Rod rotation speed (rpm) & \multicolumn{8}{|c|}{20} \\
\hline Humidity (\%) & \multicolumn{8}{|c|}{$40-50$} \\
\hline Temperature $\left({ }^{\circ} \mathrm{C}\right)$ & \multicolumn{8}{|c|}{$28-30$} \\
\hline
\end{tabular}


804 Table 2. Vibration range of groups present in scaffolds

\begin{tabular}{|c|c|c|c|}
\hline Material & $\begin{array}{l}\text { Wave number } \\
\text { range }\left(\mathrm{cm}^{-1}\right)\end{array}$ & $\begin{array}{l}\text { Associated } \\
\text { band }\end{array}$ & Scaffold present in \\
\hline \multirow{4}{*}{ PCL } & $2991-2901$ & $\begin{array}{l}\text { Asymmetric } \\
\text { stretch } \mathrm{CH}_{2}\end{array}$ & PCL, co-electrospun \\
\hline & $2879-2840$ & $\begin{array}{l}\text { Symmetric } \\
\text { stretch } \mathrm{CH}_{2}\end{array}$ & PCL, co-electrospun \\
\hline & 1753-1691 & Stretch $\mathrm{C}=\mathrm{O}$ & PCL, co-electrospun \\
\hline & $1208-1127$ & $\begin{array}{l}\text { Asymmetric } \\
\text { stretch C-O-C }\end{array}$ & PCL, co-electrospun \\
\hline \multirow[b]{2}{*}{ Gelatin } & $1702-1596$ & $\begin{array}{l}\text { Amide I } \\
(\text { Stretch } \mathrm{C}=\mathrm{O})\end{array}$ & $\begin{array}{l}\text { Gelatin face sequential, crosslinked } \\
\text { gelatin face sequential, co- } \\
\text { electrospun }\end{array}$ \\
\hline & 1588-1495 & $\begin{array}{l}\text { Amide II } \\
\text { (Vibration, } \\
\text { bending } \mathrm{N}-\mathrm{H} \text { and } \\
\text { stretch, vibration } \\
\text { C-N) }\end{array}$ & $\begin{array}{l}\text { Gelatin face sequential, crosslinked } \\
\text { gelatin face sequential, co- } \\
\text { electrospun }\end{array}$ \\
\hline
\end{tabular}


Table 3. Average apparent pore area of electrospun scaffolds.

\begin{tabular}{|c|c|c|c|}
\hline \multicolumn{4}{|c|}{ Average apparent pore area } \\
\hline Scaffold & Untreated $\left(\mu \mathrm{m}^{2}\right)$ & Cross-linked $\left(\mu \mathrm{m}^{2}\right)$ & $\begin{array}{c}\text { Reduction } \\
\text { percentage }(\%)\end{array}$ \\
\hline B0-C0 gelatin layer & $0.22 \pm 0.28$ & -- & -- \\
\hline B1 & $13.30 \pm 11.88$ & $5.31 \pm 3.53$ & 60.07 \\
\hline C1 & $7.27 \pm 5.29$ & $3.64 \pm 1.56$ & 50.00 \\
\hline
\end{tabular}

811 Table 4. Summary of mechanical properties of electrospun tubular scaffolds Yield strain (\%) Tensile strength (MPa)

\section{Untreated}

\begin{tabular}{lll} 
B0 & $44.59 \pm 13.78$ & $5.09 \pm 0.56$ \\
C0 & $44.88 \pm 0.088$ & $8.37 \pm 0.12$ \\
B1 & $38.72 \pm 3.23$ & $3.46 \pm 0.088$ \\
C1 & $37.37 \pm 3.72$ & $2.20 \pm 0.22$ \\
\hline
\end{tabular}




\begin{tabular}{lll}
\hline & & Treated \\
B0 & $46.91 \pm 13.97$ & $4.60 \pm 0.84$ \\
C0 & $43.80 \pm 1.45$ & $7.08 \pm 0.35$ \\
B1 & $29.54 \pm 9.88$ & $2.28 \pm 0.006$ \\
C1 & $33.55 \pm 4.88$ & $2.87 \pm 0.31$ \\
\hline
\end{tabular}

812 
Figures

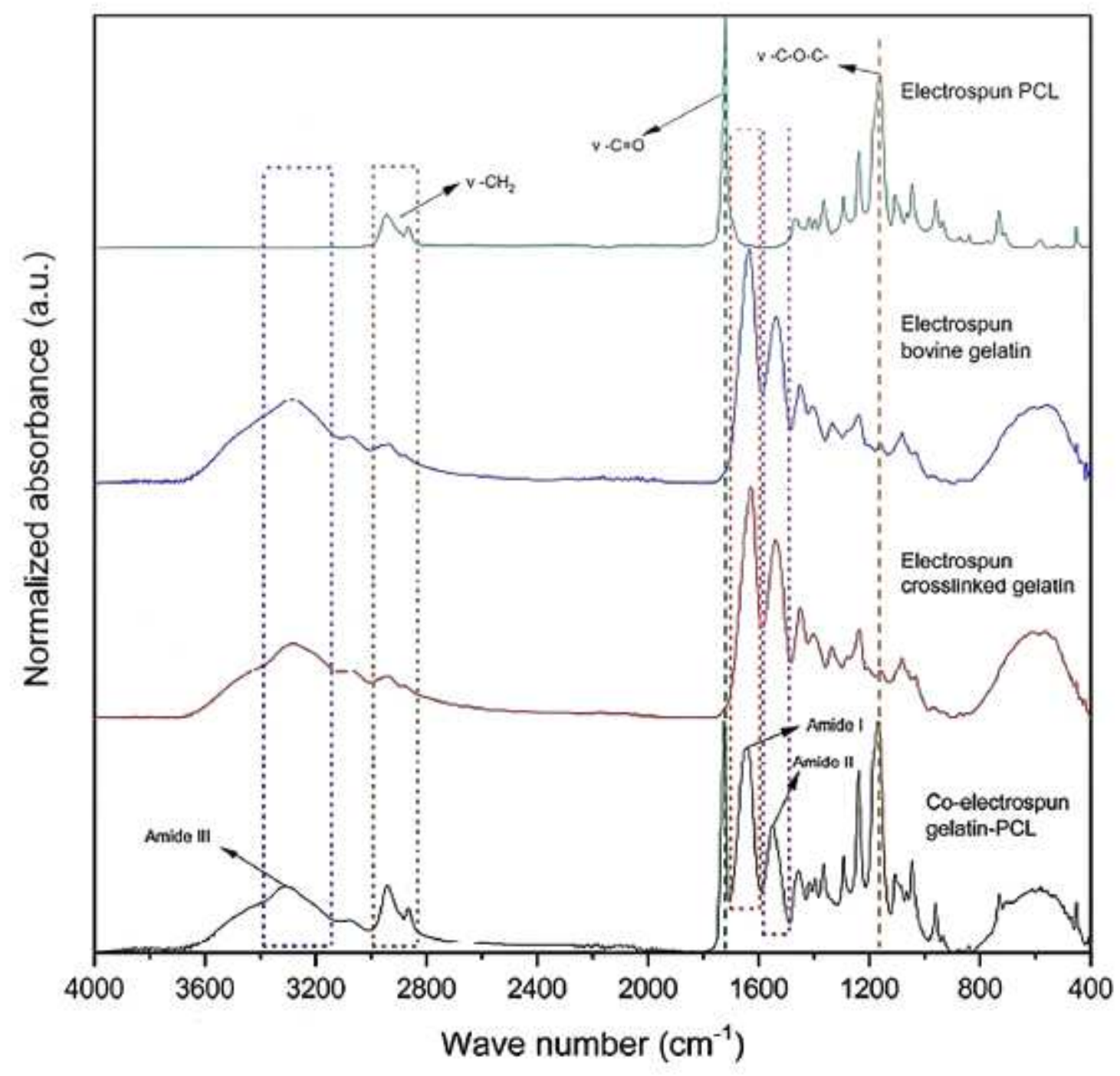

Figure 1

Normalized FTIR spectra. 

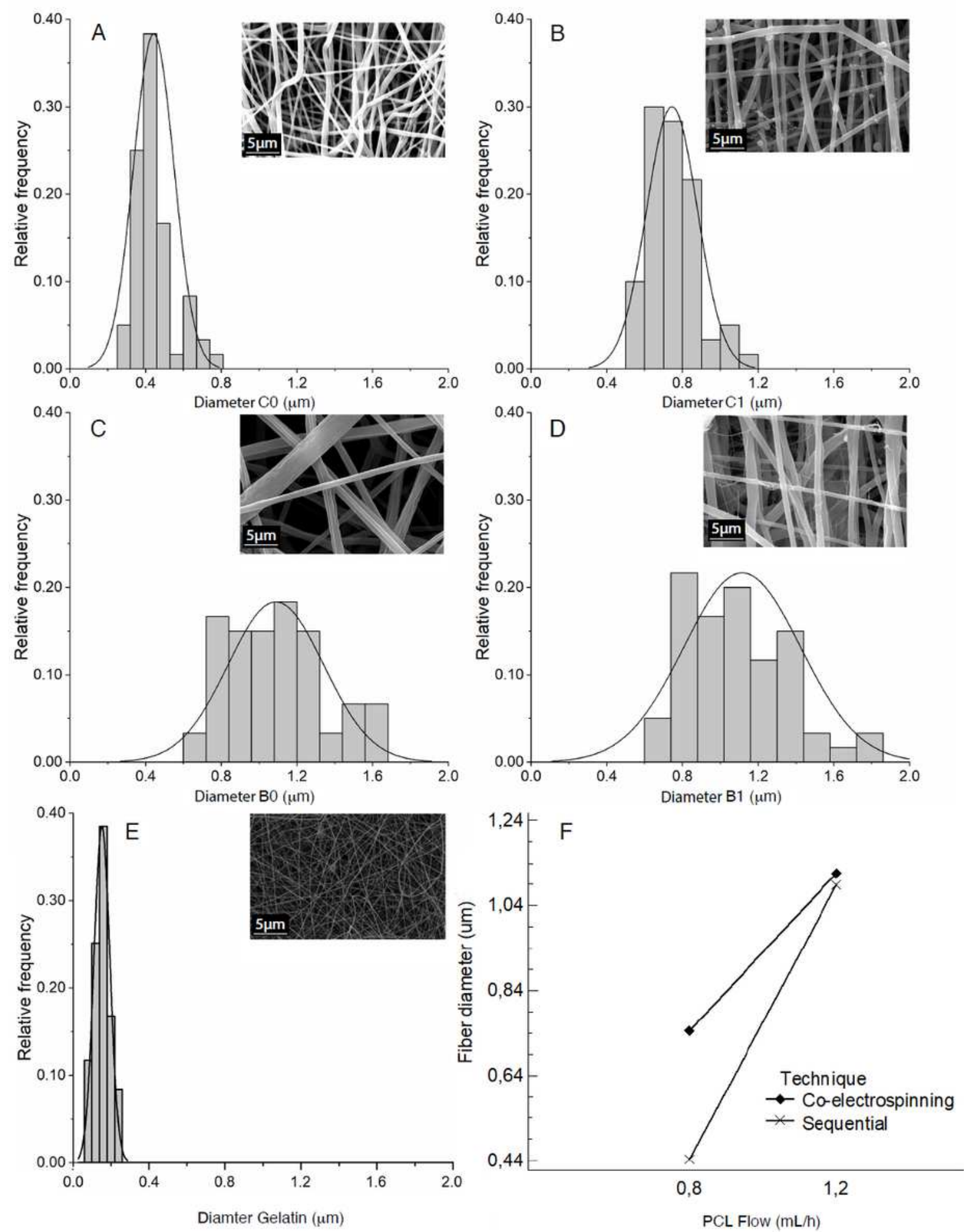

Figure 2

Histograms of the distribution of fiber diameter: A) sample with a flow of $0.8 \mathrm{~mL} / \mathrm{h}$ in the sequential configuration; B) sample with a flow of $0.8 \mathrm{~mL} / \mathrm{h}$ in the co-electrospinning configuration; C) sample with a flow of $1.2 \mathrm{~mL} / \mathrm{h}$ in the sequential configuration; D) sample with a flow of $1.2 \mathrm{~mL} / \mathrm{h}$ in the coelectrospinning configuration; E) gelatin layer in the sequential configuration; F) Interaction graph between technique and flow. 

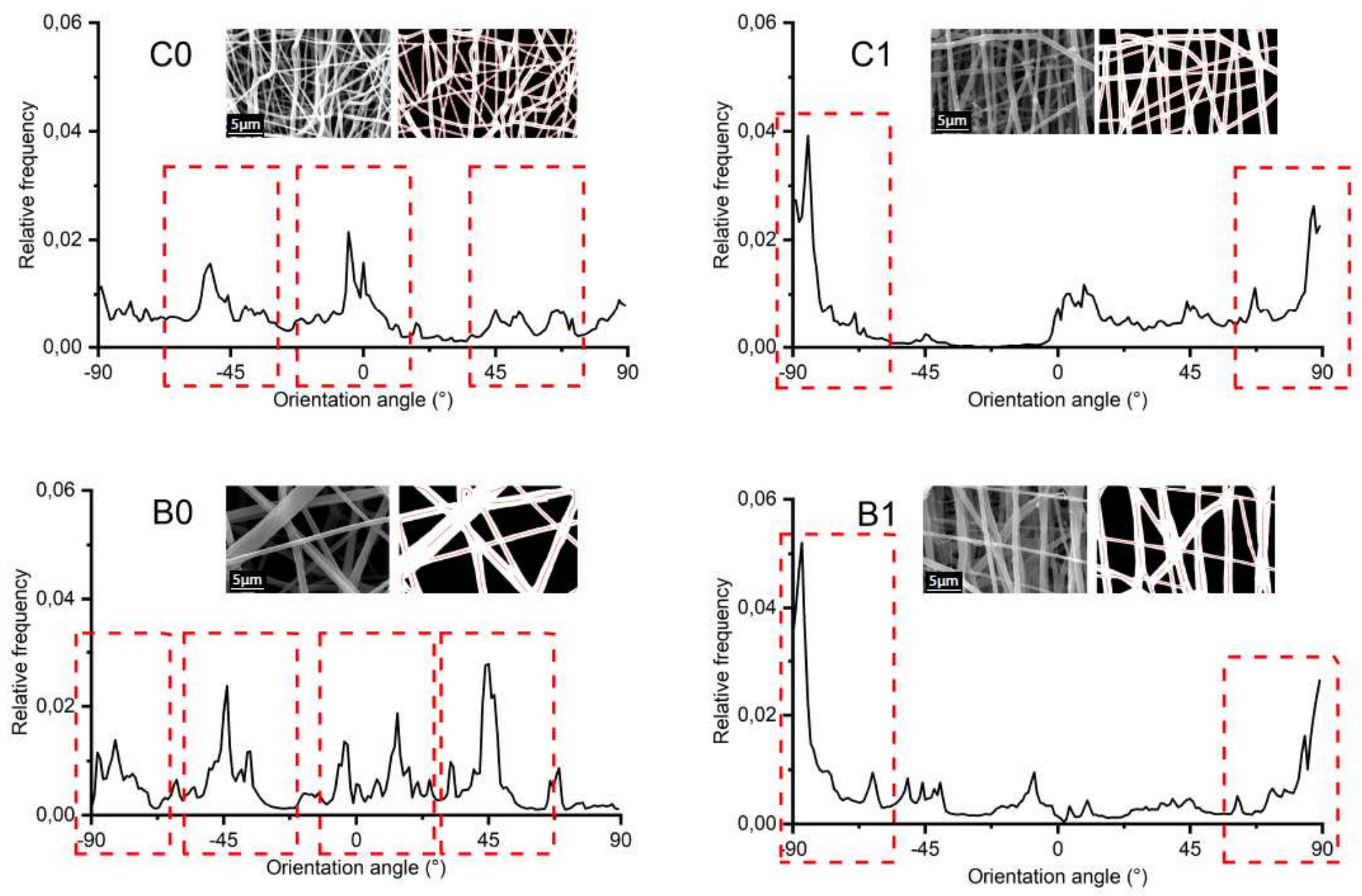

Figure 3

Normalized global frequency graphs of the fiber orientation. The fiber of sequential scaffolds shows multiple peaks of relative frequency, while in co-electrospun scaffolds predominant peaks are observed around $90^{\circ}$, indicating a greater alignment. 


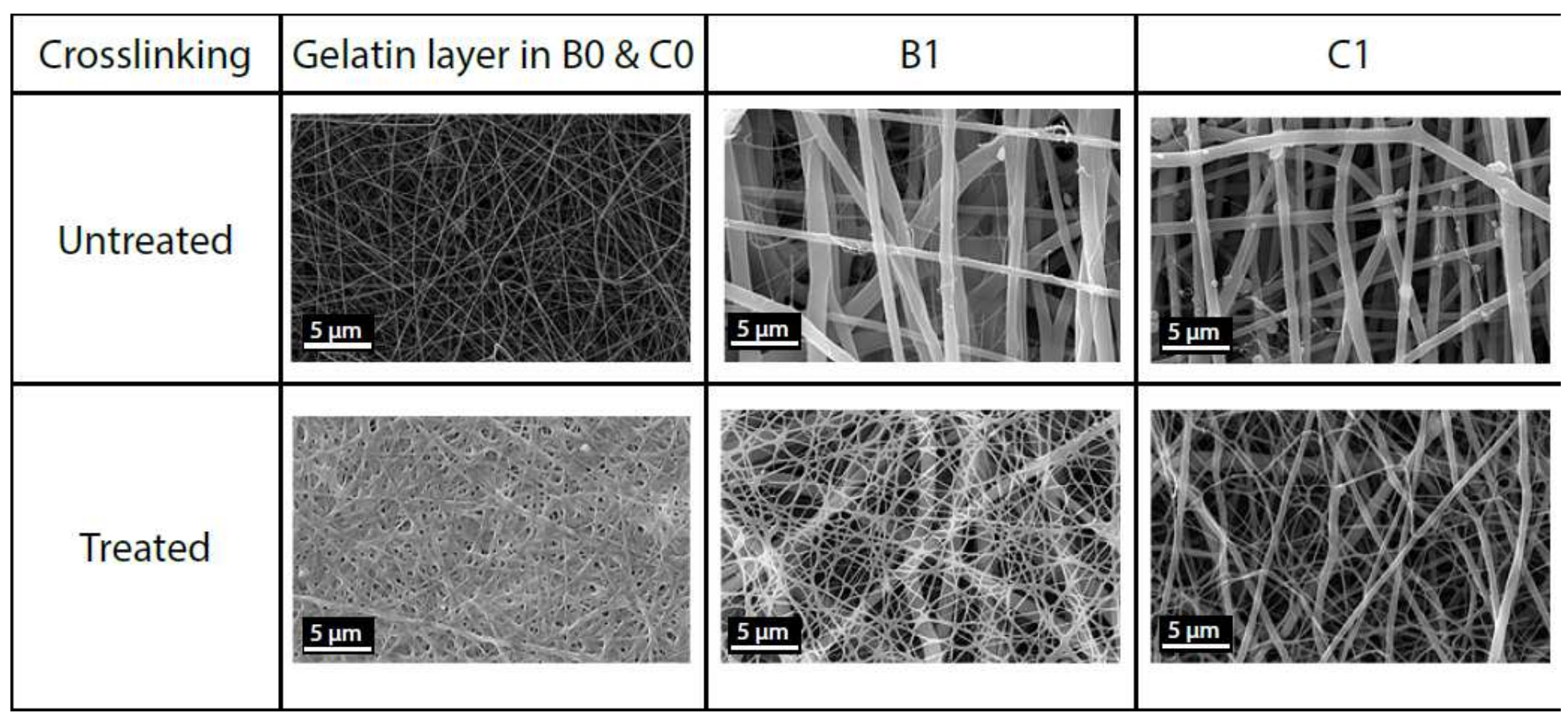

Figure 4

Comparison of SEM micrographs of the electrospun scaffold, before and after the crosslinking treatment. 

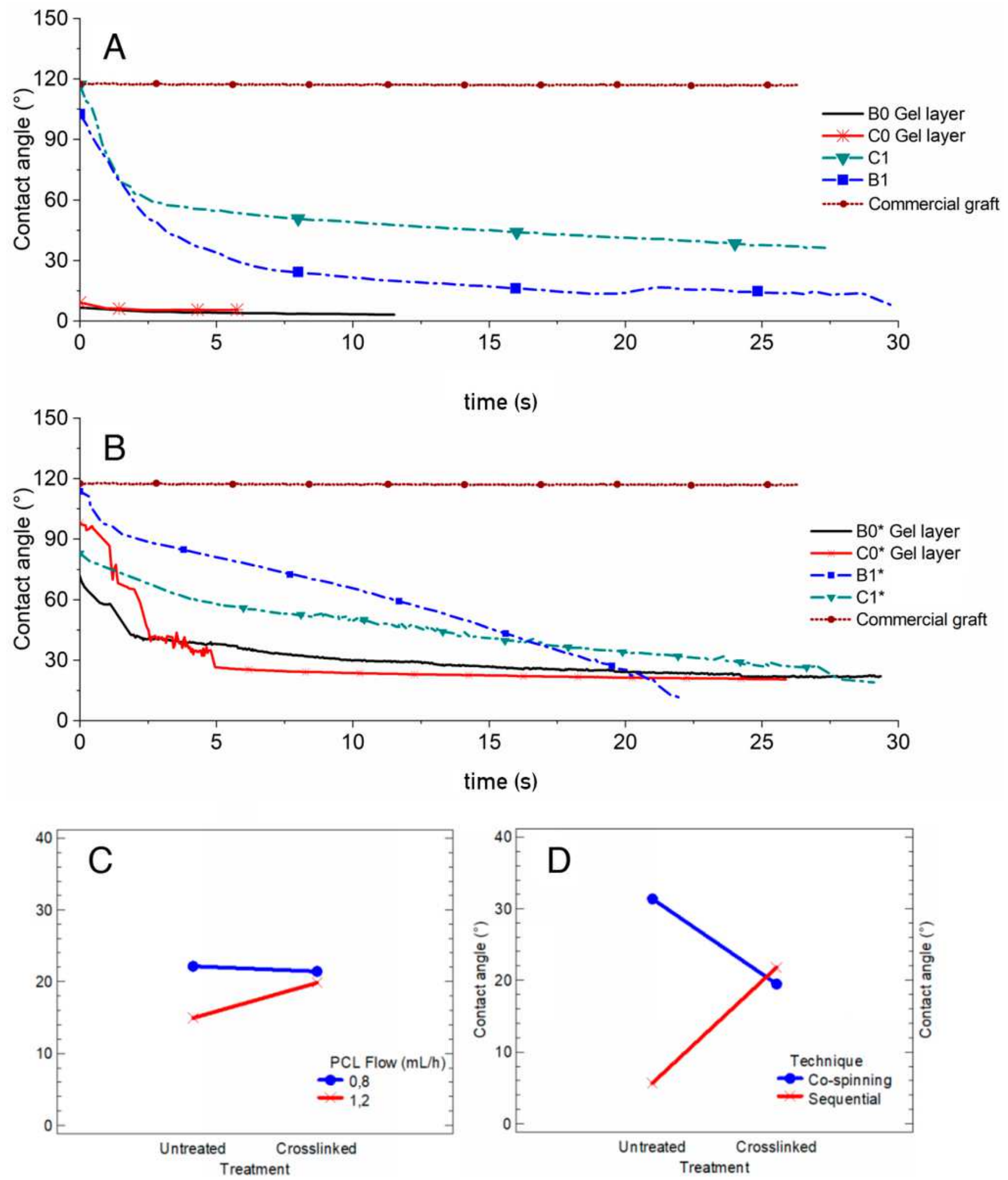

Figure 5

Contact angle vs. time curves: A) Electrospun scaffolds without crosslinking; B) Crosslinked electrospun scaffolds; C) Interaction graph according to the PCL flow; D) Interaction graph according to the technique. 

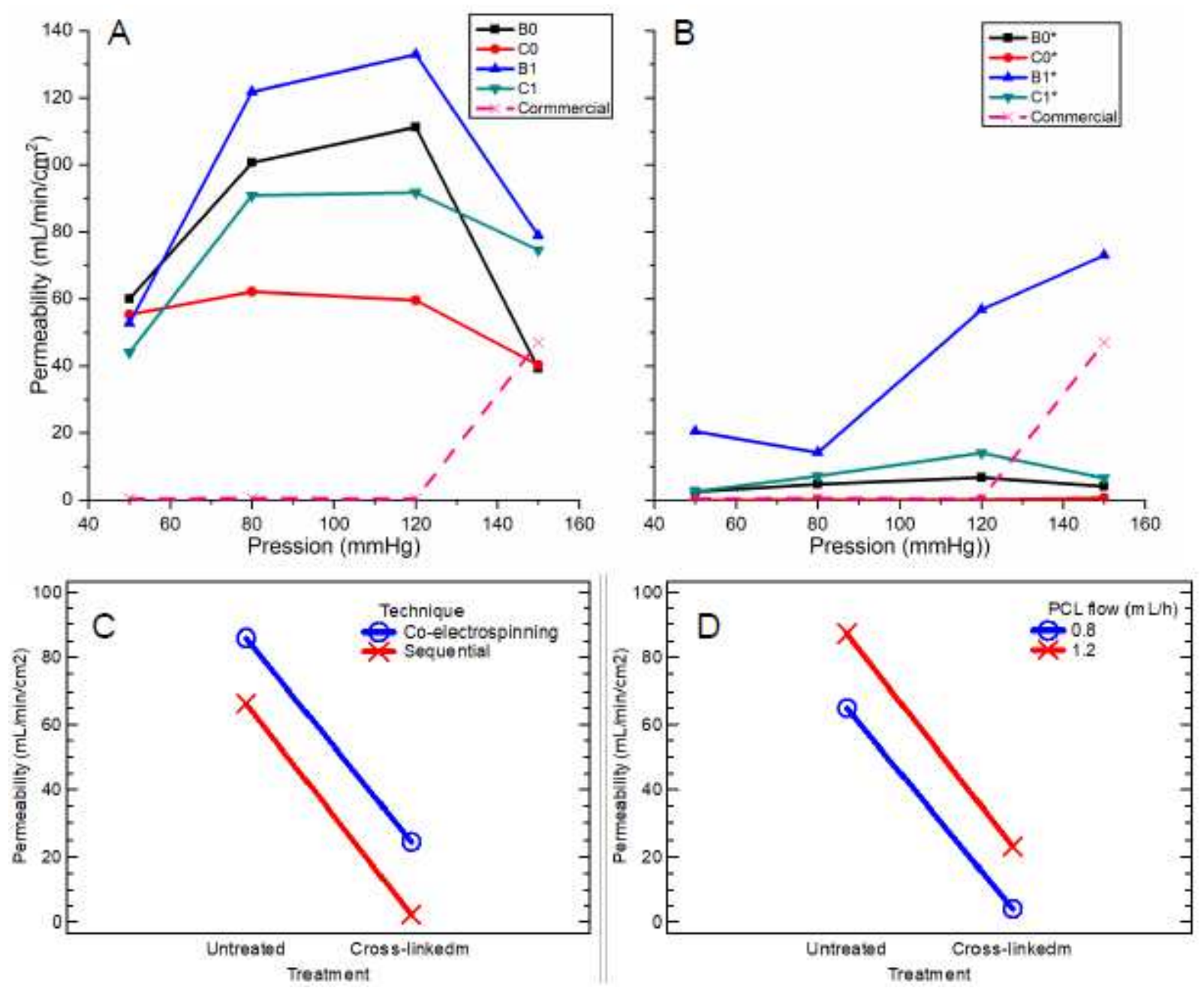

Figure 6

Static permeability: A) Electrospun scaffolds without crosslinking; B) Crosslinked electrospun scaffold; C) Interaction graph according to the technique; D) Interaction graph according to the PCL flow $(\mathrm{mL} / \mathrm{h})$. 

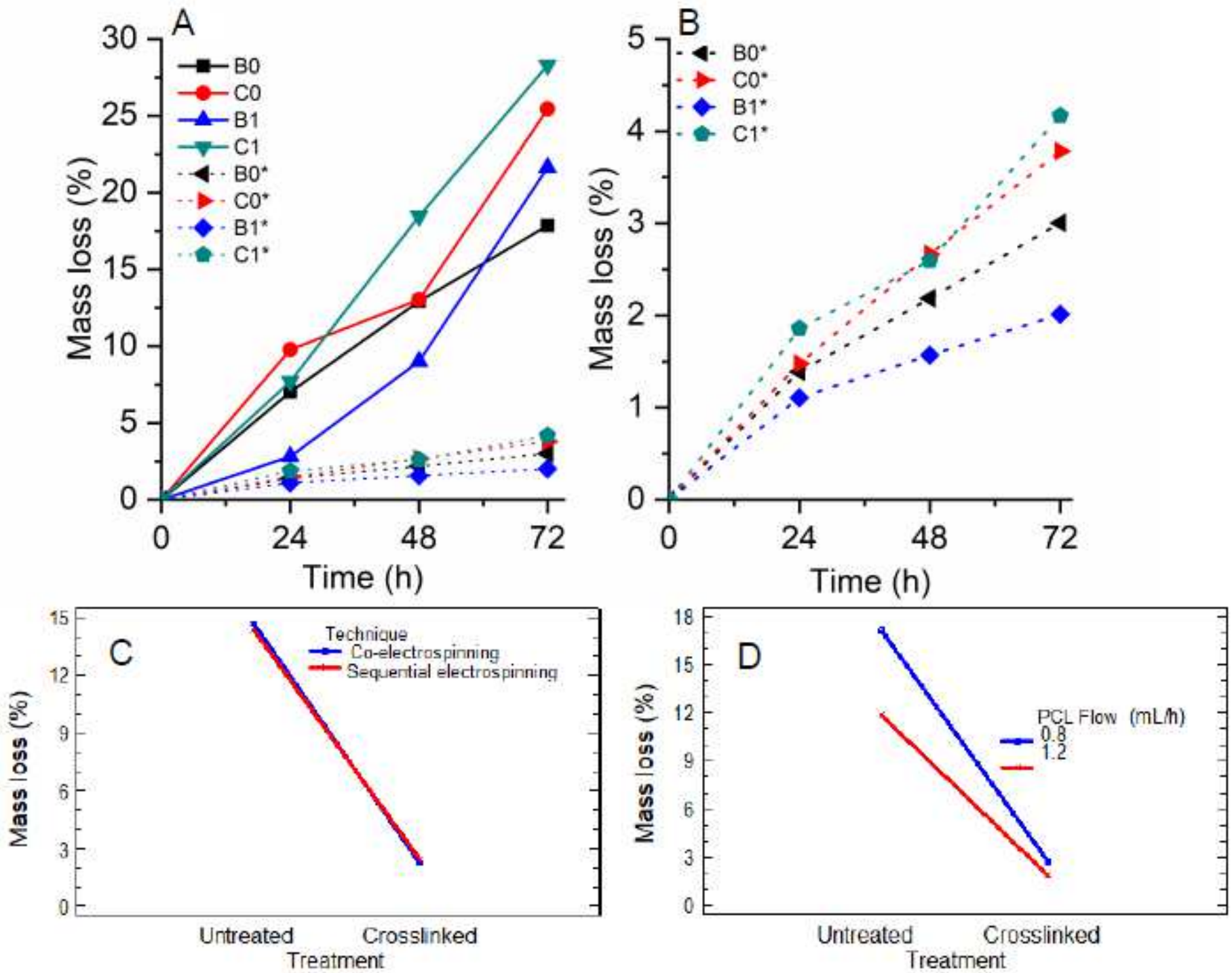

Figure 7

Mass loss of electrospun scaffolds: A) samples without treatment; B) cross-linked samples; C) Interaction graph according to the technique; $D)$ Interaction graph according to the PCL flow ( $\mathrm{mL} / \mathrm{h}$ ). 
A
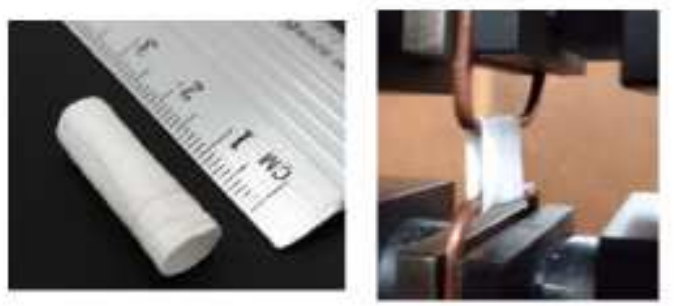

C
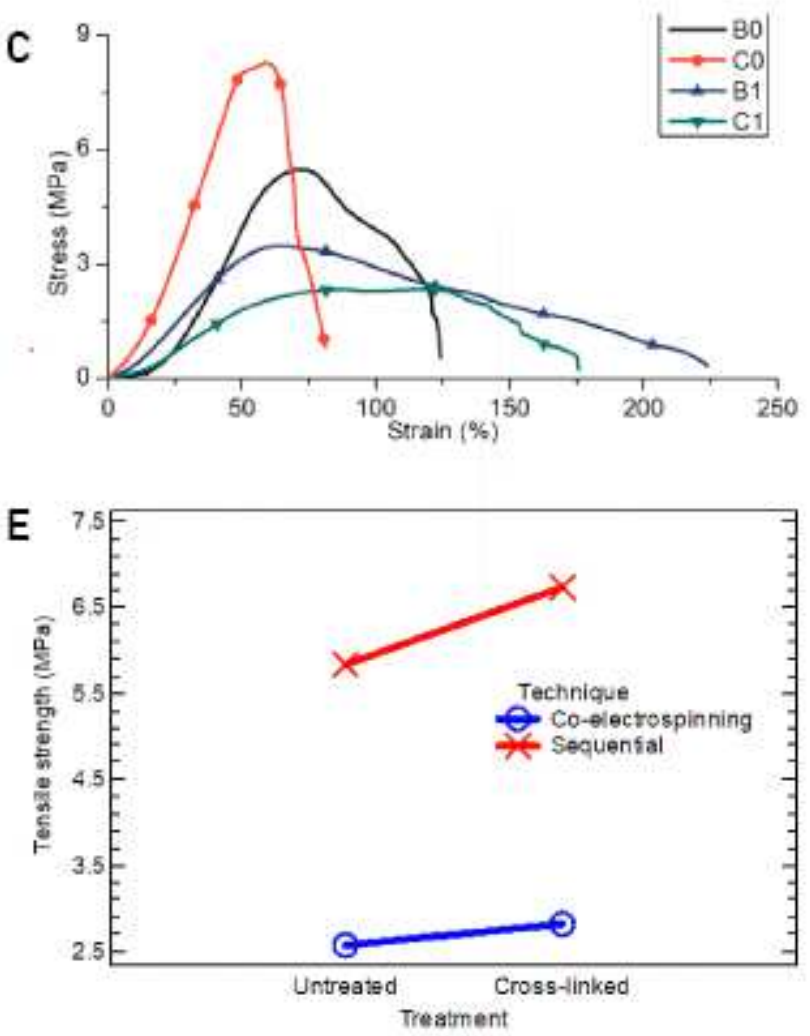

B

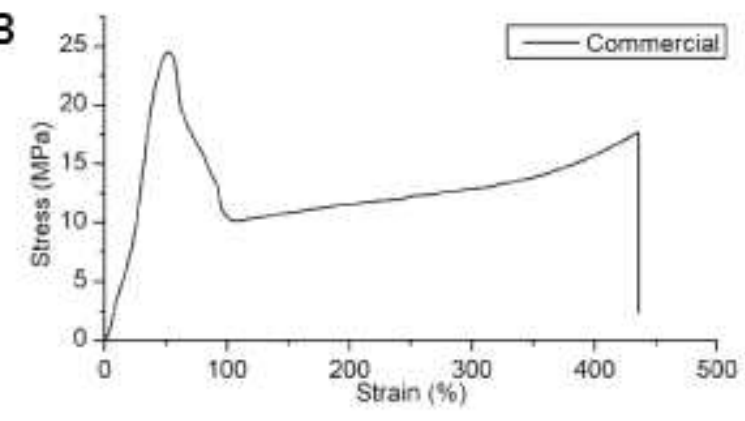

D

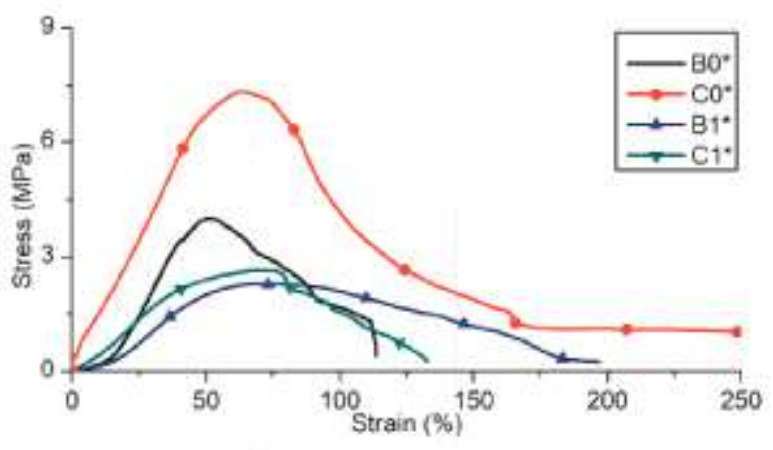

$\mathbf{F}$

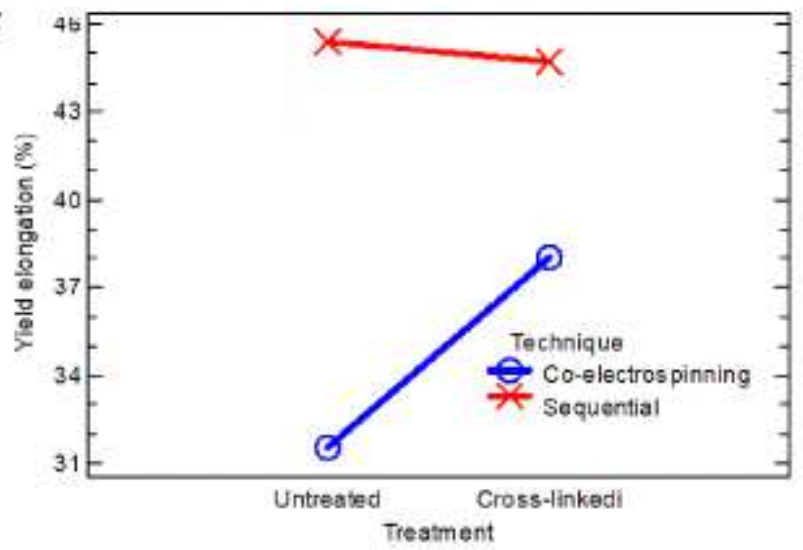

Figure 8

Stress curves vs deformation for tubular scaffolds: 794 A) test of traction; B) commercial sample; C) sample without treatment; D) sample with crosslinking treatment; E) Interaction graph for tensile strength according to the technique; F) Interaction graph for yield elongation according to the technique 
A)

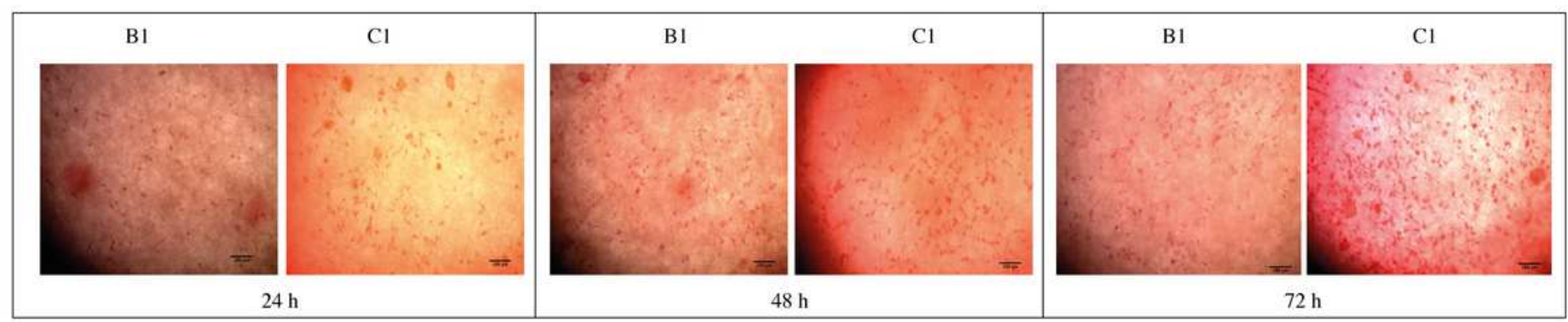

B)

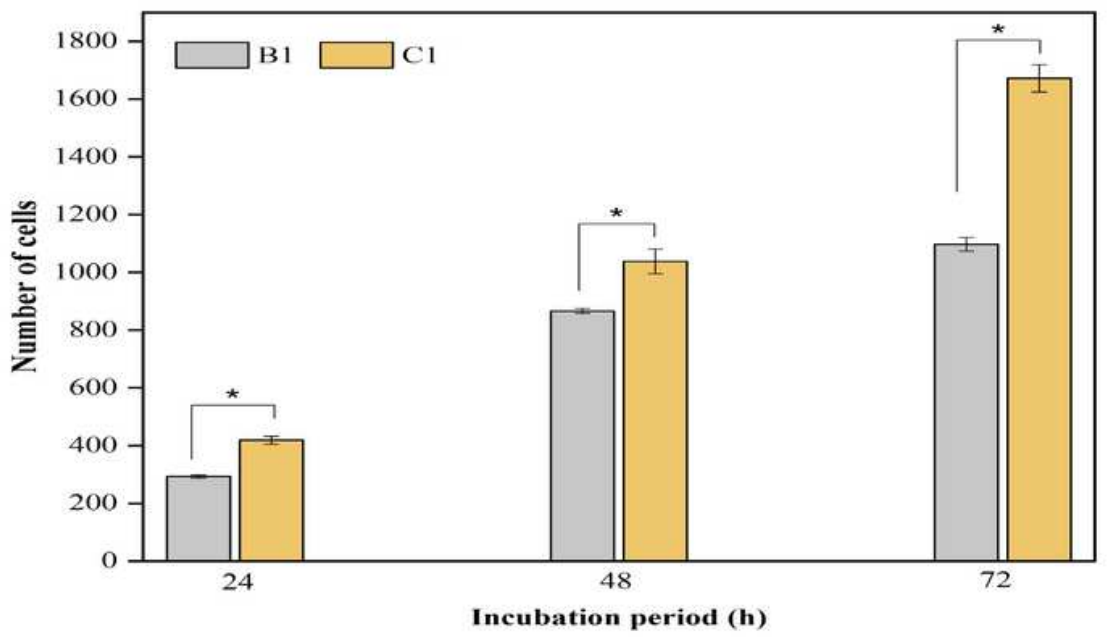

Figure 9

Cross-linked B1 and C1 membranes interacting with 3 T3 fibroblasts:A) bright-field images of fibroblasts; B) cell growth rate at incubation periods of 24,48 , and $72 \mathrm{~h}$. 